\title{
ANALISIS FAKTOR-FAKTOR YANG BERHUBUNGAN DENGAN ANGKA KESEMBUHAN PENGOBATAN PADA PASIEN TUBERKULOSIS PARU DI KAB. PADANG PARIAMAN
}

\author{
Efri Yeni \\ Program Studi Magister Ilmu Kesehatan Masyarakat, Universitas Andalas \\ Email : efri_gm@yahoo.co.id
}

Submitted : 28-01-2020, Reviewer:16-02-2020, Accepted: 17-02-2020

\begin{abstract}
ABSTRAK
Angka keberhasilan pengobatan pasien TB di Kabupaten Padang Pariaman belum mencapai target yaitu tahun 2013 sebesar 83\%, tahun 2014 menurun menjadi 82\% sementara target yang ditetapkan yaitu 85\%. Penelitian ini bertujuan untuk menganalisis faktor-faktor yang berhubungan dengan angka kesembuhan pengobatan pada pasien Tuberkulosis paru di Kab. Padang Pariaman.

Penelitian ini merupakan penelitian dengan menggabungkan antara metode penelitian kuantitatif dengan pendekatan cross sectional dan dilanjutkan dengan penelitian kualitatif. Penelitian ini dilakukan bulan Maret 2017 - Juni 2017 di Kabupaten Padang Pariaman. Populasi dalam penelitian ini adalah seluruh pasien TB paru yang menjalani pengobatan di Kab. Padang Pariaman triwulan 2 dengan jumlah sampel 60 sampel. Teknik pengambilan sampel dengan multistage sampling. Data dianalisis secara univariat dan bivariat dengan menggunakan uji chi square.

Hasil penelitian diketahui sebagian kecil responden $(11,7 \%)$ gagal dalam kesembuhan pengobatan pada pasien tuberkulosis dan $(13,3 \%)$ memiliki sikap negatif. kurang dari separoh responden $(26,7 \%)$ memiliki tingkat pengetahuan yang rendah mengenai pengobatan tuberkulosis. Kurang dari separoh responden $(28,3 \%)$ memiliki kinerja pengawas minum obat yang tidak baik terhadap pengobatan pasien tuberkulosis. Analisis bivariat diketahui terdapat hubungan tingkat pengetahuan, sikap dan kinerja PMO dengan kesembuhan pengobatan pada pasien Tuberkulosis paru di Kab. Padang Pariaman ( $p$ value < 0,05). Data kualitatif diketahui pelaksanaan program TB pada perencanaan program yang kurang matang, keterbatasan dana, kurangnya kerjasama lintas program dan lintas bidang di dinas kesehatan serta pembinaan terhadap sektor kesehatan swasta belum dilakukan. Pada faktor masyarakat adalah pengawas minum obat kurang aktif dalam memotivasi pasien dan pendampingan pasien TB dalam berobat, serta keluarga yang kurang aktif dalam memotivasi penderita untuk sembuh.

Penelitian ini menyimpulkan terdapat hubungan tingkat pengetahuan, sikap dan kinerja PMO dengan kesembuhan pengobatan. Perlu adanya dukungan dengan peningkatan pelaksaanaan promosi kesehatan untuk peningkatan pengetahuan pasien TB mengenai pengobatan TB.
\end{abstract}

Kata Kunci $\quad$ : Tuberkulosis, kesembuhan pasien, pengawas minum obat 


\section{PENDAHULUAN}

Tuberkulosis (TB) sampai dengan saat ini masih merupakan salah satu masalah kesehatan di dunia walaupun upaya penanggulangan TB telah dilaksanakan di banyak negara sejak tahun 1995 (Kemkes, 2015). Tuberkulosis paru (TB paru) merupakan satu penyakit menular yang dapat menyebabkan kematian. TB Paru adalah penyakit infeksi kronis yang disebabkan oleh infeksi Mycobacterium tuberculosis (M.tb). Kuman ini paling sering menyerang organ paru. Munculnya pandemic HIV/AIDS di dunia menambah permasalahan TB. Koinfeksi dengan HIV akan meningkatkan risiko kejadian TB secara signifikan. Pada saat yang sama, kekebalan ganda kuman TB terhadap obat anti TB (Multi Drug Resistance = MDR) semakin menjadi masalah akibat kasus yang tidak berhasil disembuhkan. Keadaan ini membuat terjadinya epidemi TB yang sulit ditangani (Kemkes,2008)

Menurut laporan World Health Organization (WHO) tahun 2015, di tingkat global diperkirakan sekitar 9,6 juta orang menderita TB baru dan 1,5 juta meninggal karena TB (termasuk 320.000 kematian di antara orang HIV-positif dan 480.000 TB Resistan Obat). Indonesia merupakan negara ke-2 terbanyak penderita TB setelah India (WHO, 2015).

Kasus TB di Indonesia pada tahun 2015 dengan insidensi 399 per 100.000 penduduk, diperkirakan ada 1 juta kasus TB baru pertahun. Jumlah kematian akibat TB diperkirakan 41 per 100.000 penduduk atau sama dengan 100.000 kematian pertahun (Kemkes, 2015) sedangkan menurut Riskesdas, 2013, prevalensi TB paru di Sumatera Barat pada tahun 2013 adalah sebesar $0.2 \%$ atau 200/100.000 penduduk. Selain itu, TB terjadi pada lebih dari $70 \%$ usia produktif (15-54 tahun), dalam hal ini kerugian ekonomi yang disebabkan oleh TB cukup besar (Werdhani, 2002).

Angka kesembuhan pengobatan mengindikasikan persentase pasien baru TB Paru terkonfirmasi bakteriologis yang sembuh setelah selesai masa pengobatan, diantara pasien baru TB paru terkonfirmasi bakteriologis yang tercatat.(Pedoman Nasional Pengendalian TB, 2014).

Rendahnya angka kesembuhan pengobatan menandakan bahwa masih banyak penderita TB paru yang belum sembuh, hal ini tidak hanya berpengaruh pada penularan yang akan semakin banyak terjadi pada keluarga penderita maupun orang-orang di lingkungan penderita tetapi ditakutkan akan terjadi kekebalan ganda terhadap Obat Anti Tuberkulosis sehingga proses kesembuhan akan semakin sulit (Profil Kesehatan Indonesia, 2015).

Salah satu penentu proses kesembuhan TB Paru adalah kepatuhan minum obat. Kepatuhan minum obat memiliki pengaruh yang besar terhadap proses kesembuhan, karena merupakan salah satu faktor yang berpengaruh terhadap kesembuhan (Rosiana, 2013). Penentu lain dalam meningkatkan angka kesembuhan TB Paru adalah keberadaan atau peran dari Pengawas Menelan Obat (PMO).

\section{METODE PENELITIAN}

Penelitian ini merupakan penelitian kombinasi model concurrent embedded dengan penelitian kuantitatif sebagai metode primer dan penelitian kualitatif sebagai metode sekunder. Penelitian kuantitatif menggunakan analisis statistik dengan desain penelitian Cross Sectional Study dan penelitian kualitatif untuk mendapatkan informasi mendalam mengenai upaya dalam peningkatan angka kesembuhan pengobatan pada pasien TB Paru di Kab. Padang Pariaman.

Populasi pada penelitian ini adalah seluruh pasien TB paru yang menjalani pengobatan di Puskesmas Pasar Usang, Puskesmas Lubuk Alung, Puskesmas Pauh Kambar dan Puskesmas Sintuk pada triwulan 3 tahun 2016 yaitu sebanyak 126 orang.

Untuk metode kualitatif, yang menjadi informen penelitian adalah Kepala Bidang Pengendalian dan pemberantasan Penyakit, 
Kasi Pengendalian dan pemberantasan penyakit, Wasor TB di Dinas Keseshatan Kabupaten Padang Pariaman, Kepala Puskesmas, Pemegang program TB di puskesmas, dan Penderita TB dan PMO. Instrumen pada penelitian kualitatif adalah : Pedoman Wawancara dan telaah dokumen dan Alat bantu lain berupa alat pencatat, kamera dan alat perekam.

Variabel penelitian terdiri dari variabel independen variabel dependen yaitu tingkat Pengetahuan, Sikap dan Kinerja Pengawas Minum Obat (PMO) sedangkan variable dependenya adalah Angka Kesembuhan pengobatan Pasien TB Paru.

Data yang terkumpul sebelum dianalisis dilakukan pengolahan data terlebih dahulu melalui tahapan editing, coding, entry dan cleaning data. Data dianalisis secara univariat, bivariat dan multivariat. Analisis univariat untuk mendapatkan gambaran distribusi frekuensi dari setiap variabel yang diteliti. Analisis bivariat bertujuan untuk melihat hubungan variabel independen dengan variabel dependen Uji statistik yang digunakan adalah Chi-square dengan tingkat kemaknaan $\alpha=0,05$. Analisis multivariat, digunakan untuk menganalisis hubungan beberapa variabel independen dengan satu variabel dependen dengan uji statistik yang digunakan adalah regresi logistik berganda.

\section{HASIL DAN PEMBAHASAN}

Gambar 1. Distribusi karakteristik responden

\begin{tabular}{lcc}
\hline Karakteristik & Frekuensi (f) & $\begin{array}{c}\text { Persentase } \\
(\%)\end{array}$ \\
\hline Jenis Kelamin & & \\
Laki-laki & 31 & 51,7 \\
Perempuan & 29 & 48,3 \\
Umur & & \\
$17-25$ tahun & 3 & 5 \\
26-35 tahun & 5 & 8,3 \\
36-45 tahun & 11 & 18,3 \\
$\geq 46$ tahun & 41 & 68,3 \\
Pendidikan & & \\
Tidak tamat SD & 3 & 5
\end{tabular}

\begin{tabular}{lcc} 
Tamat SD & 23 & 38,3 \\
Tamat SMP & 23 & 38,3 \\
Tamat SMA & 9 & 15 \\
Tamat Perguruan & 2 & 3,3 \\
Tinggi & & \\
Pekerjaan & & \\
Tidak Bekerja & 25 & 41,7 \\
Pedagang & 12 & 20 \\
Buruh & 7 & 11,7 \\
Petani & 14 & 23,3 \\
PNS & 1 & 1,7 \\
Lainnya & 1 & 1,7 \\
Jumlah & $\mathbf{6 0}$ & $\mathbf{1 0 0}$ \\
\hline & &
\end{tabular}

Karakteristik Responden
38,3

15

,3

41,7

20

23,3

1,7

1,7

100 


\section{Gambar 1Distribusi Frekuensi Kesembuhan Pengobatan pada Pasien Tuberkulosis}

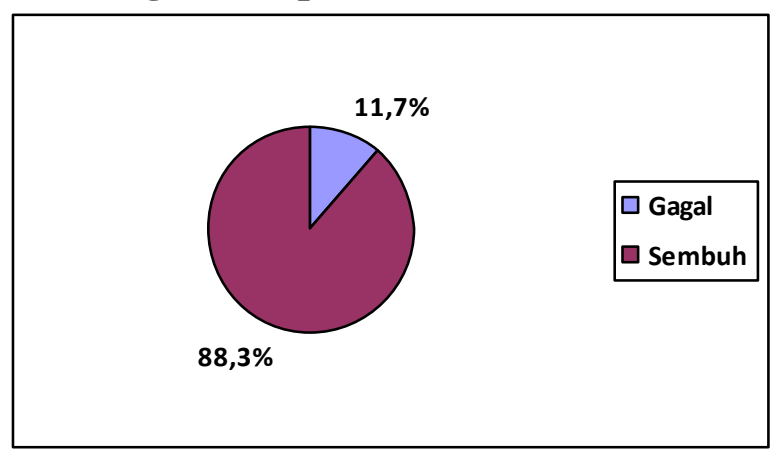

\section{Gambar2 Distribusi Frekuensi Responden Berdasarkan Tingkat Pengetahuan pada Pasien Tuberkulosis Kabupaten Padang Pariaman}

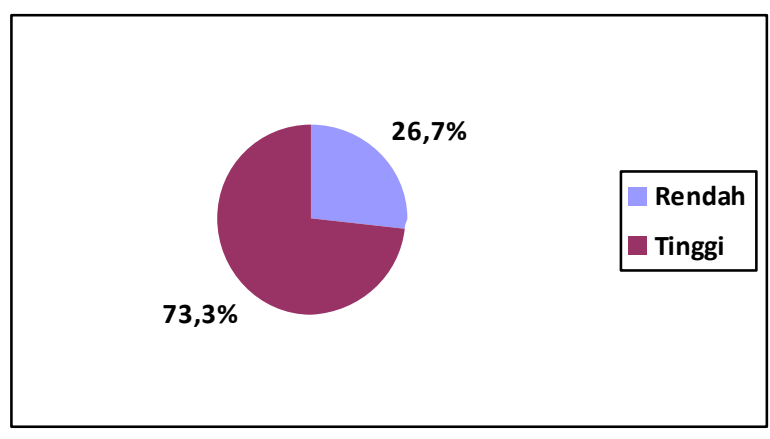

Gambar 3 Distribusi Frekuensi Responden Berdasarkan Sikap pada Pasien Tuberkulosis Padang Pariaman

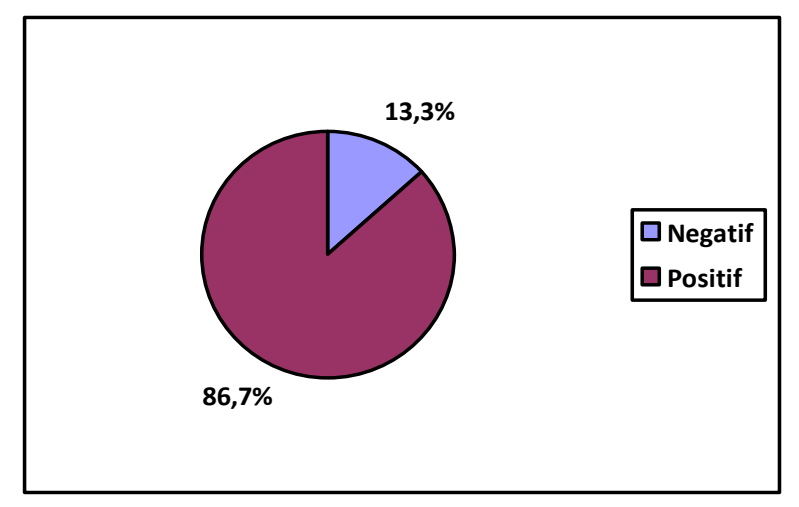

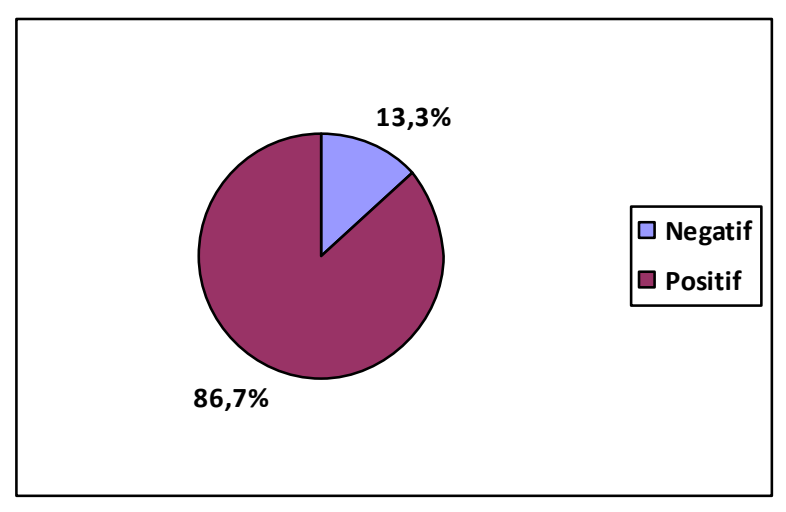

Distribusi Frekuensi Responden Berdasarkan Kinerja Pengawas Minum Obat pada Pasien Tuberkulosis Padang Pariaman

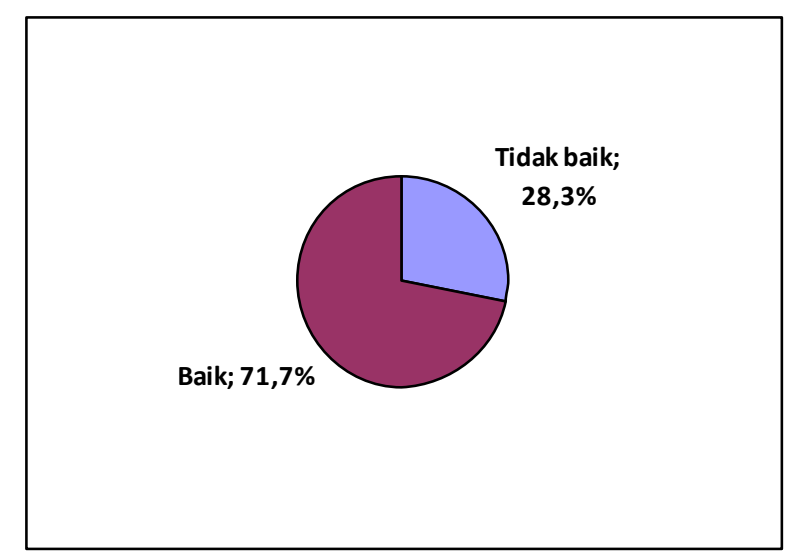

Hasil penelitian kualitatif ini terdiri dari komponen perencanaan (Planning), pengorganisasian (Organizing), penggerakkan pelaksanaan (Actuating) dan pemantauan penilaian (Controlling Evaluating).

Penanggung jawab semua program dan fasilitas kesehatan di Kabupaten Padang Pariaman adalah Kepala Dinas kesehatan, termasuk juga program TB, yang secara teknis dibantu oleh Kepala Bidang dan Kepala Seksi Pengendalian dan Pemberantasan Penyakit, sedangkan sebagai pelaksana teknis harian adalah seorang wasor TB kabupaten. Dengan tugas mulai dari perencanaan, pengorganisasian, 
pelaksanaan serta monitoring dan evaluasi termasuk melakukan bimbingan teknis terhadap semua fasilitas pelayanan kesehatan yang ada di wilayah kabupaten Padang Pariaman.. Perencanaan program TB paru didasarkan kepada rencana yang di buat oleh Dinas Kesehatan baik jangka menengah ataupun jangka pendek untuk program TB paru, serta kegiatan lain dalam meningkatkan pencapaian angka kesembuhan dalam pengobatan penderita TB paru.

Kesembuhan pasien TB ditentukan dengan mematuhi petunjuk dalam menelan obat TB, mengikuti tahap awal pengobatan dengan teratur, meminum obat sesuai dengan dosis yang ditentukan, teratur berobat ke puskesmas dan mematuhi jadwal pemeriksaan dahak yang telah ditentukan.

Hasil wawancara mendalam yang dilakukan peneliti mengenai pelaksanaan program kesembuhan pengobatan pasien TB diketahui pengetahuan penderita tentang penyakit TB terutama cara penularan penyakit serta sikap penderita TB paru yang negatif untuk melakukan pemeriksaan dahak dan masih banyak pengawas minum obat kurang aktif dalam memotivasi pasien dan pendampingan pasien TB dalam berobat menyebabkan masih ada penderita TB paru yang gagal dalam pengobatan. Hal ini terjadi karena pengawas minum obat (PMO) memiliki kesibukan pekerjaan di rumah untuk mencari tambahan pendapatan rumah tangga karena pendapatan yang tidak cukup sehingga terkadang melewatkan untuk mendampingi pasien TB dalam mengkonsumsi obat.

Hasil penelitian diketahui kurang dari separoh responden $(26,7 \%)$ memiliki tingkat pengetahuan yang rendah mengenai pengobatan tuberkulosis. Berdasarkan analisis kuesioner diketahui pertanyaan pengetahuan responden yang terendah adalah cara penularan penyakit TB paru yaitu $21,7 \%$ dan cara pemakaian obat TB paru $51,7 \%$.
Persentase responden yang gagal dalam pengobatan tuberkulosis lebih tinggi pada responden dengan sikap yang negatif yaitu $(50 \%)$ dibandingkan yang positif $(5,8 \%)$. Hasil uji statistik diperoleh nilai $p=$ 0,004 ( $p$ value < 0,05) maka disimpulkan bahwa ada hubungan yang signifikan antara sikap dengan kesembuhan pengobatan pada pasien TB paru.

Hasil penelitian ini sama dengan penelitian yang dilakukan oleh Hamdi (2010) yang menyatakan terdapat hubungan kegagalan pasien dalam pengobatan TB dengan sikap terhadap pengobatan tuberkulosis paru. Penelitian Muniroh (2013) menyatakan pasien yang tidak sembuh dalam pengobatan TB paru disebabkan oleh kurangnya minat pasien dalam menjalani pengobatan berdasarkan anjuran yang ditetapkan. Lette (2013) yang menyatakan terdapat hubungan antara sikap dengan kesembuhan berobat pada penderita TB yaitu nilai $\mathrm{p}=0,001(\mathrm{p}<0,05)$.

Persentase responden yang gagal dalam pengobatan tuberkulosis lebih tinggi pada responden dengan kinerja pengawas minum obat yang tidak baik yaitu $(35,3 \%)$ dibandingkan yang baik $(2,3 \%)$. Hasil uji statistik diperoleh nilai $p=0,001$ ( $p$ value < 0,05) maka disimpulkan bahwa ada hubungan yang signifikan antara kinerja pengawas minum obat dengan kesembuhan pengobatan pada pasien TB paru.

Apabila pengobatan terputus tidak sampai enam bulan, penderita sewaktuwaktu akan kambuh kembali penyakitnya dan kuman tuberkulosis menjadi resisten sehingga membutuhkan biaya besar untuk pengobatannya (Hiswani, 2002). Pengelola program TB di puskesmas di Kabupaten Padang Pariaman juga kurang aktif dalam membantu PMO. Hal ini di sebabkan karena, Pengelola Program TB di Puskesmas Kab. Padang Pariaman belum seluruhnya menggunakan sistem "Jemput Bola" dimana langsung mengantarkan obat ke rumah pasien jika pasien tidak datang mengambil obat ke puskesmas jika sudah 1 (satu) bulan 
pengobatan serta memberikan dukungan dan pengertian kepada penderita agar patuh dalam minum obat. Hal ini berdampak kepada penderita yang tidak patuh minum obat. Selanjutnya, melakukan penjaringan untuk mengetahui Penderita TB di wilayah kerja Puskesmas.

\section{KESIMPULAN \& SARAN}

Perencanaan program TB paru masih belum maksimal. Kerjasama lintas program dan lintas bidang untuk promosi tentang TB paru masih kurang, kualitas petugas TB dan petugas puskesmas lainnya serta kurangnya sosialisasi ke masyarakat tentang TB paru merupakan masalah dalam perencanaan program TB di dinas kesehatan Padang Pariaman.

\section{DAFTAR PUSTAKA}

Achmadi, U.F. 2005. Manajemen Penyakit Berbasis Wilayah. Jakarta : Penerbit Buku Kompas.

Crofton J, Horne N, Miller F. 2002.Tuberkulosis Klinis, Edisi 2. Jakarta: Penerbit; Widya Medika.

Departemen Kesehatan RI. 2015. Pedoman Nasional Pengendalian Tuberkulosis. Jakarta: Depkes RI Direktorat Jendral Pengendalian Penyakit dan Penyehatan Lingkungan.

Dinas Kesehatan Kabupaten Padang Pariaman. 2014. Laporan program penanggulangan TBC. Padang Pariaman; Dinas Kesehatan Kab. Padang Pariaman.

Dinas Kesehatan Kabupaten Padang Pariaman. 2015. Profile Dinas Kesehatan Kabupaten Padang Pariaman : Dinas Kesehatan Kabupaten Padang Pariaman

Dinas Kesehatan Propinsi Sumatera Barat. 2012. Laporan program penanggulangan TBC. Padang; Dinas Kesehatan Propinsi Sumatera Barat.
Hastono, S.P. 2007. Analisis Data Kesehatan. Fakultas Kesehatan Masyarakat. Universitas Indonesia

Kemenkes RI. 2013. Riset Kesehatan Dasar. Jakarta : Ditjen Linbang Kes.

Lemeshow, S. 1997. Besar Sampel dalam Penelitian Kesehatan. Gajah Mada University Press.

Muniroh, Nuha, Siti Aisiah, Mifbakhudin. 2013 Faktor-faktor yang berhubungan dengan Kesembuhan Penyakit Tuberculosis (TBC) paru di wilayah kerja Puskesmas Mankang Semarang Barat. Jurnal Keperawatan Komunitas, Vol. 1. No $1: 33-42$

Notoatmojo S. 2003. Ilmu Kesehatan Masyarakat Prinsip-Prinsip Dasar. Jakarta: Rineka Cipta. 2007. Pendidikan dan Perilaku Kesehatan. Jakarta: Rineka Cipta.

Riset Kesehatan Dasar. 2013. hhtp://www.depkes.go.id/resources /download/ general/Hasil\%20Riskesdas $\% 2020$ 13.pdf, 20 Januari 2017

Rosiana, Anny. Hubungan Tingkat Ekonomi dengan Kejadian Tuberkulosis Paru di Puskesmas Kaliwungu Kabupaten Kudus. JIKK Vol. 4 No. 2 Juli 2013. 35-44.

Saharrieng, R.A, Kepel, B.J, Ratag, B.T, 2013. Faktor-faktor yang berhubungan dengan Status Kesembuhan Pasien Tuberkulosis Paru di Wilayah Kerja Puskesmas Tamako, Puskesmas Manganitu, dan Puskesmas Tahuna Timur di Kabupaten Kepulauan Sangihe. Universitas Sam Ratulangi

Sastroasmoro S, Sofyan I. 2011. Dasar-dasar Metodologi Penelitian Klinis. Jakarta: Binarupa Aksara

Wahyuni, D.S. Hubungan Kondisi Fisik Rumah dan Karakteristik Individu dengan Kejadian Tuberkulosis Paru BTA Positif di Puskesmas Ciputat Kota Tangerang Selatan 
Tahun 2012. BIMKI Vol 1 No. 1 2012.

WHO. 2015. Global Tuberculosis Report 2015

Departemen Kesehatan RI. (2005). Pharmaucetical Care Untuk Penyakit Tuberculosis. Direktorat Bina Farmasi

Komunitas Klinik. Ditjen Bina Bina Farmasi dan Alkes.

Jakarta.

Tesis Program Pasca Sarjana UI, Depok.

Umar, 2007, Faktor-faktor yang berhubungan dengan kinerja bidan di desa dalam pelayanan Antenatal Care (ANC) berdasarkan standar pelayanan kebidanan di Kabupaten Batang Hari Jambi tahun 2007. Tesis Program Pasca Sarjana UI, Depok.

Wahjosumitjo, 1987, Kepemimpinan dan Motivasi. Ghalia Indonesia, Jakarta.

Winardi, J, 2008 , Motivasi Pemotivasian dalam Manajemen, PT Raja Grafindo Persada, Jakarta

Wibowo, 2011, Manajemen Kinerja, Rajawali Pers, Jakarta

Yunita, 2013 Tentang faktor-faktor yang mempengaruhi kinerja bidan desa dalam deteksi dini resiko tinggi ibu hamil pada pelayanan antenatal di Kabupaten Bengkulu selatan Tahun 2013. Tesis Program Pasca Sarjana Universitas Diponegoro . 